\title{
Cruise Control of Phase Irrigation Motor Using SparkFun Sensor
}

\author{
https://doi.org/10.3991/ijoe.v13i08.7318 \\ Nagarjuna Telagam $\left({ }^{\varpi}\right)$ \\ Institute of Aeronautical Engineering, Hyderabad, India \\ nagarjuna473@gmail.com \\ Menakadevi Nanjundan \\ Hindustan College of Engineering and Technology, Coimbatore, India \\ Nehru Kandasamy, Soma Naidu \\ Institute of Aeronautical Engineering, Hyderabad, India
}

\begin{abstract}
Water Conservation and labor-saving is the key issue of irrigation in India. This Shot paper proposes an automatic irrigation control based on microcontroller and GSM technology. This wireless design provides high reliability. We have used SparkFunsoil moisture sensor SEN 13322 which is interfaced with RobokartAruduino Mega 2560 microcontroller. The soil information such as dry and wetness of the irrigation field is given to Elementz SIM 800 GSM module to an authorized wireless telephone from the remote area to the monitoring system based on smart sensor network. With the help of soil wet and dry information we are controlling the invento DC motor automatically with the help of sending message in smart phone.
\end{abstract}

Keywords-Microcontroller, Soil Sensor, Relay, DC motor

\section{Introduction}

Fresh water resources are unevenly distributed in India. Annual precipitation in India with snowfall of 4,000 billion cubic meters [BCM]. Nearly $75 \%$ of this [3000bcm] occurs during the monsoon season generally in the middle of June and September. Water scenario is now fast changing as a result of increasing population, rising demand for irrigation in India to raise high-yielding varieties of crops.

The automatic irrigation system does the work quite efficiently. Once it is installed in the agricultural field, the water distribution to crops and nurseries becomes easy and doesn't require any human support to perform the operations permanently. Sometimes automatic irrigation can also be performed by using mechanical appliances such as clay pots or bottle irrigation system. It's very hard to implement irrigation systems because they are very expensive and complex in their design. 


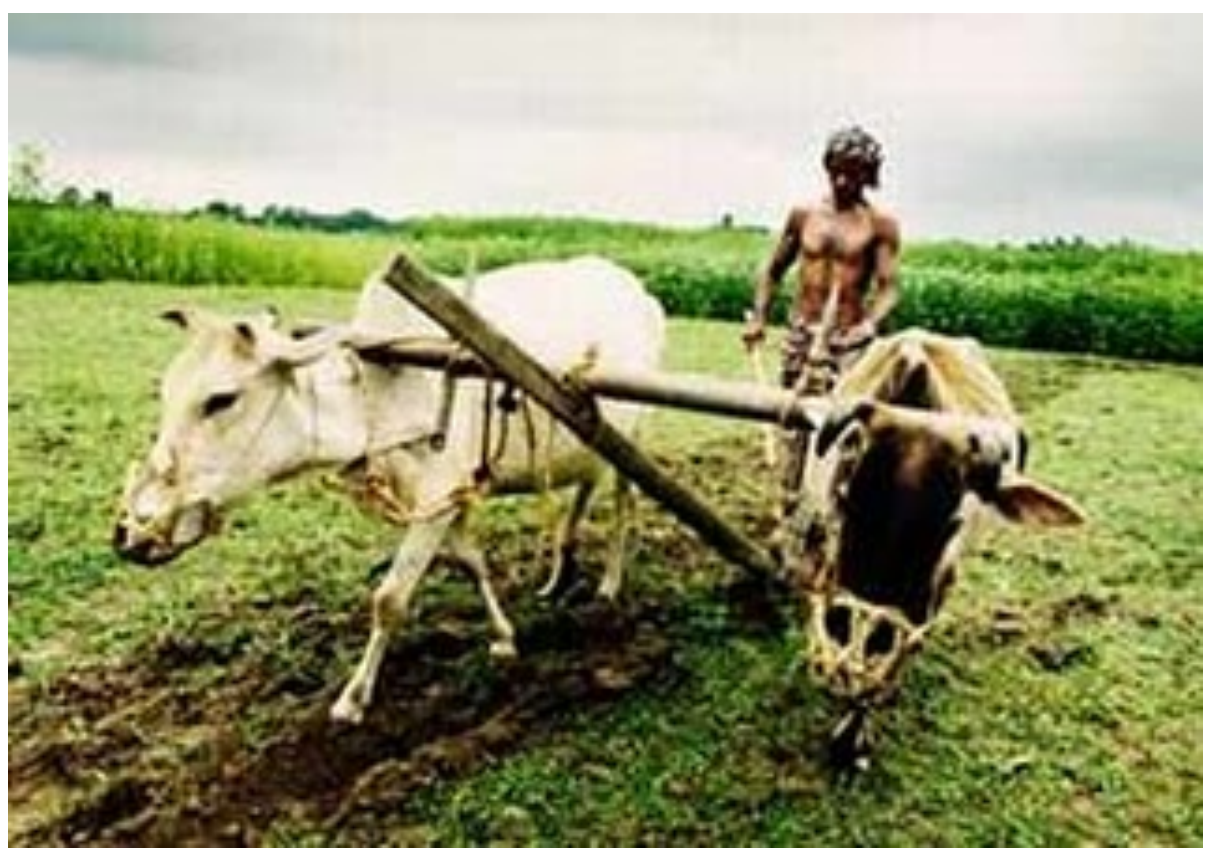

Fig. 1. Present Irrigation System in India

\section{Implementation}

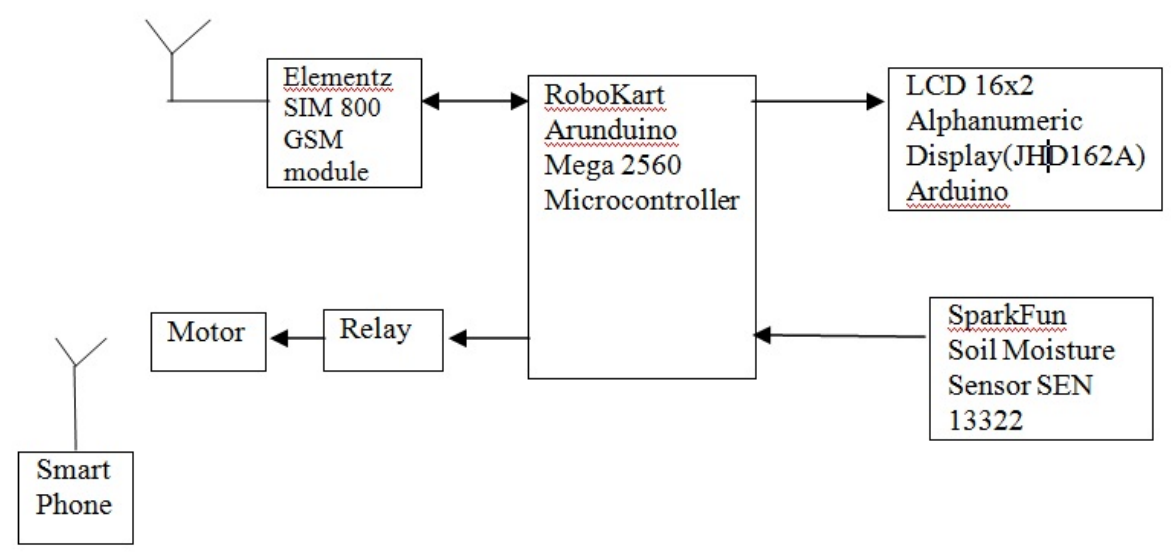

Fig. 2. Block diagram of Automatic Irrigation system

The other components are basically rectifier, filter, transformer, LEDs, capacitors, resistors and Voltage regulator.

The detail about its working is given below. 
Step 1: Initializing the hardware kit, the operation starts by the microprocessor initialization.

Step 2: The GSM module is initialized.

Step 3: Initializing the serial communication port.

Step 4: Initializing the soil moisture sensor.

Step 5: Soil sensor the moisture content of the soil and the result is send to the microcontroller.

Step 6: the obtained result is send to the user using GSM module.

Step 7: the result is again recorded in GSM module from the soil sensor

Step 8: Controlling the DC motor based on the input of the soil sensor

Step 9: After step 7, the control again comes to the step 5.

Step 10: The operation is accomplished successfully.

The GSM Based automatic irrigation system is a project in which we get update status of the operation carried out in the agricultural fields via SMS with the help of a GSM modem. We used LCD which indicates the soil sensor data, whether is wet or dry. The soil SparkFun soil sensor is interfaced with the Robokart microcontroller of port 3 .

\section{Hardware Implementation}

We interface our project with GSM technology to smart phone. We came to the conclusion that our design would require a micro-controller in our base station in order to receive wireless messages and process the information. With this in mind, we decided it would be a more practical and simple to purchase a single hardware board that could perform the functions. The microcontroller which we are using is the Robokart microcontroller i.e. Aruduino Mega 2560. The other components used are relay, motors, LCD display and the soil sensor which sends the soil information. The voltage regulator 7805 is also used. The resistors, capacitors, diodes is also used.The idea of the project is to implement an automatic irrigation system by sensing the moisture of the soil.

The working of the circuit is as follows. The soil moisture sensor is inserted in the soil. Depending on the quality of the sensor, it must be inserted near the roots of the plant. The soil moisture sensor measures the conductivity of the soil. Wet soil will be more conductive than dry soil. The soil moisture sensor module has a comparator in it.The voltage from the prongs and the predefined voltage are compared and the output of the comparator is high only when the soil condition is dry. This output from the soil moisture sensor is given to the analogue input pin (Pin $2-$ RA0) of the microcontroller. The microcontroller continuously monitors the analogue input pin.When the moisture in the soil is above the threshold, the microcontroller displays a message mentioning the same and the motor is off.When the output from the soil moisture sensor is high i.e. the moisture of the soil is less. This will trigger the microcontroller and displays an appropriate message on the LCD and the output of the microcontroller, which is connected to the GSM module.With the help of GSM 
module, the relay coil gets energized and turns on the motor. When the moisture of the soil reaches the threshold value, the output of the soil moisture sensor is low and the motor is turned off. The system is also designed to warn when the moisture is very high than the threshold and the soil is too wet, which is dangerous for the plant.

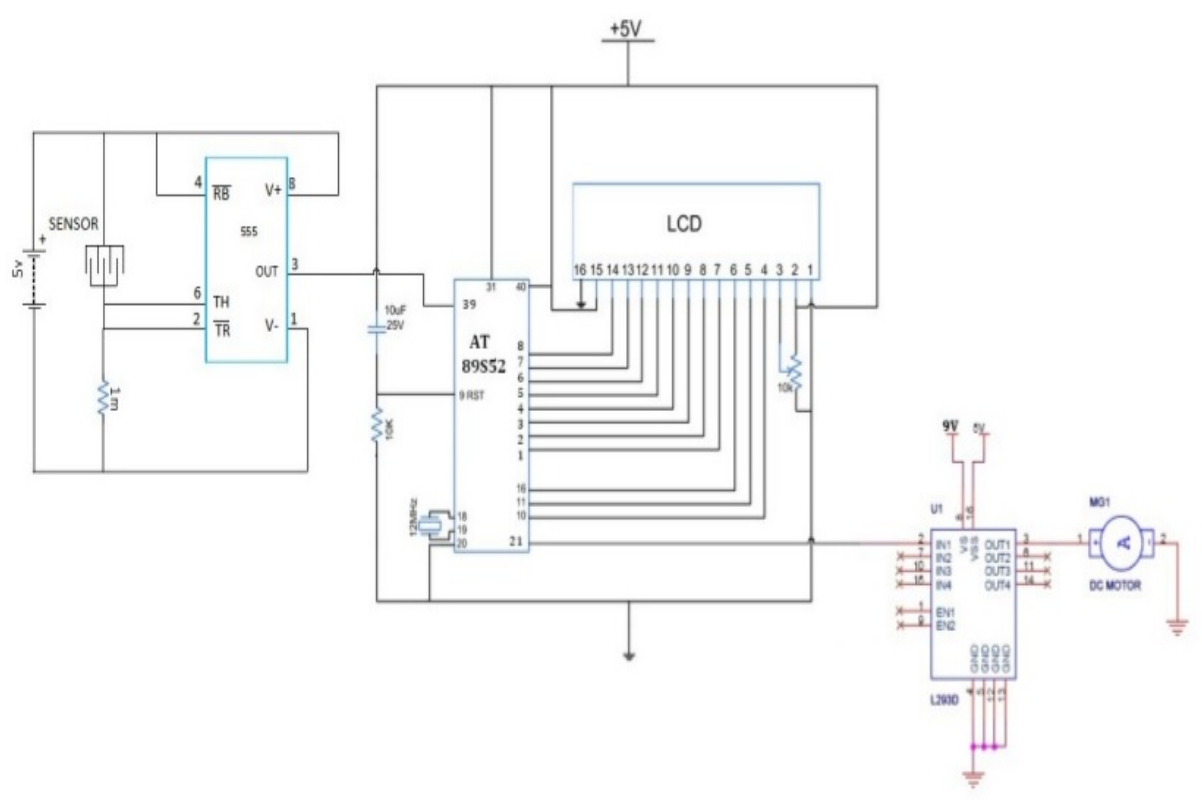

Fig. 3. Schematic diagram of Automatic Irrigation system

\section{Software Implementation}

The software used for this project is Keil $\mathrm{C}$ cross compiler as it has a microcontroller. This compiler is basically used for the conversion of the high level language to the object code. The embedded $\mathrm{C}$ language is used for the programs which are given to the microcontroller. The embedded $\mathrm{C}$ language used is for giving instructions.

\section{Application}

- The circuit can be used to measure the loss of moisture in the soil over time due to evaporation and intake.

- Minimizes water waste and improves plant growth.

- The circuit is designed to work automatically and hence, there is no need for any human intervention. 
- The project is intended for small gardens and residential environment. By using advanced soil moisture sensor, the same circuit can be expanded to large agricultural fields.

- Irrigation in fields

- Irrigation in gardens, parks.

- Very efficient for paddy, rice fields

- Pisiculture

\section{Advantages}

- Reduce labor

- Improved Lifestyle

- Assists in the management of higher flow rates

- More accurate cut-off

- Reduced runoff of water and nutrients

- Reduced costs for vehicles used for irrigation.

- Works according to soil condition

- Can handle heavy loads up to 7 Amp

\section{$7 \quad$ Disadvantages}

- Cost.

- Reliability

- Increased channel maintenance.

- Applicable only for large farms

- Have limited life after installation due to detoriation of plastic component in a hot, arid climate when exposed to UV light.

\section{$8 \quad$ Costing}

In this project we used Robokart Arduino Mega 2560microcontroller which will cost of 21 US dollars. The circuit diagram printing on the PCB board will be for microcontroller, motor, Relay, LCD display so for each of it will be a total of 48 US dollars. The components used such as capacitors, resistors and other components will 10 US dollars. The cost of the transformer is 1.54 US Dollars. We used Elementz SIM GSM tool which will cost 23.26 US Dollars. The Spartz soil sensor which we used cost 5.59 US dollars. The battery is used will costs us approximately 2-3 US Dollars. So the overall total costing for the project will be of 110 US Dollars. 


\section{Conclusions}

The microcontroller based drip irrigation system proves to be a real time provides to be real time feedback which monitors and controls all the activities of drip irrigation system efficiently. The present proposal is a model for modernize the agriculture industries at a mass scale with optimum expenditure. Using this system one can save manpower, water to improve production and ultimately profit.

\section{Future Extension}

The working of the project is basically dependent on the output of the humidity sensors. Whenever there is a need of excess water in the desirable field (RICE crops) then it will not be possible by using the sensor technology. For this we will have to adopt the DTMF technology. By using this we will be to irrigate the desired field and desired amount.

\section{References}

[1] "The PIC Microcontroller and Embedded systems" by Muhammad Ali Mazidi and Janice Gillespie Mazidi, Pearson Education.

[2] www.microchip.com

[3] www.beyondlogic.org

[4] www.wikipedia.org

[5] www.howstuffworks.com

[6] http://agriculture.vic.gov.au/agriculture/farm-management/soil-andwater/irrigation/automatic- irrigation

[7] https://www.slideshare.net/stk25/ppt-for-automatic-plant-irrigation-syste

[8] https://www.robokart.com/index.php?route=product/product\&product_id=66

\section{Authors}

Nagarjuna Telagam (corresponding author) is with the Electronics and Communication Engineering Department, Institute of Aeronautical Engineering, Hyderabad, India. He is a Research Scholar in Sathyabama University and is interested in the following topics: Wireless Communications, MIMO, OFDM, GFDM. Currently, He is working as Assistant Professor. He Received his B.Tech degree from JNTU University/ Narayana Engineering College. He received his master degree from Anna University/ Loyola Institute of Technology. He is Anna University rank holder (20) for M.E degree in 2013. He published papers in different Referred Journals (nagarjuna473@gmail.com)

Menakadevi Nanjundan is with the Electronics and Communication Engineering Department, Hindustan College of Engineering and Technology, Coimbatore, India. She is a Research Fellow and is interested in the following topics: Digital Image pro- 
cessing, Wireless communications. Currently She is working as assistant professor. Her professional experience about 4 and half years in the field of teaching. She completed my master degree M.E - communication system in Loyola institute of technology Chennai in the year 2013. She is Anna University Rank holder (22) for M.E degree. She finished her Bachelor degree B.E - electronics and communication engineering in muthayammal engineering college. (menakadevin@gmail.com)

U. Somanaidu received B.TECH. degree in Electronics and Communications Engineering from JNTU University, Kakinada, in 2011, Currently doing M. Tech. in PEC Engineering college, from JNTUK University, Kakinada. His research interests include VLSI and Embedded systems.(somanaidu.409@gmail.com)

Nehru K received his Bachelor Degree in Erode Sengunthar Engineering College, Anna University in 2005. And he obtained his Master Degree in R.M.K Engineering, Anna University in 2007. And he also obtained outstanding master student at that year. He is obtained his Ph.D in 2014 at Faculty of Information and Communication Engineering, Anna University, India. His main research interest is in the area of Low Power VLSI, Testing of VLSI Circuits, FPGA Design, CAD for VLSI, Signal processing. He has published papers on these topics in various international journals. (email:nnehruk@gmail.com).

Article submitted 19 June 2017. Published as resubmitted by the authors 27 July 2017. 